\title{
Study of Methods of Biodiesel Neutralization with Aqueous Solution of Lymonic Acid
}

\author{
Viktor Polishchuk, Svetlana Tarasenko, Ievgen Antypov*, Nataliya Kozak, \\ Andrii Zhyltsov, Oleksandr Okushko \\ National University of Life and Environmental Sciences of Ukraine, \\ Ukraine, 03041, Kyiv, Heroiv Oborony Str., 12, phone: 044-527-87-48
}

\begin{abstract}
At the article is to determining an effective way to neutralize biodiesel and install optimal and rational parameters of biodiesel neutralization. The investigation of the efficiency of biodiesel neutralization was carried out by mixing it with aqueous citric acid solution (volumetric method) and by spraying an aqueous solution of citric acid over a layer of biodiesel (aerosol method).
\end{abstract}

\section{Formulation of the problem}

During the process of the biodiesel (methyl ether) production, according to the traditional technology, for accelerating the methanolysis, a catalyst (mainly alkaline homogeneous) must be used, which, however, itself does not react to methanolysis, but only accelerates it. Therefore, in the biodiesel produced, the mentioned catalyst remains completely, causing corrosion of the engine. Corrosion products, falling into the gap between the cylinder and the piston, lead to their abrasive wear. One of the ways to remove a catalyst from diesel biofuels under the traditional technology of its production is to neutralize it with organic or inorganic acids, followed by the removal of formed salts.

\section{An analysis of last researches}

Different methods have been developed for the purification of biodiesel from catalyst residues, the main ones being so-called "wet" and "dry" biodiesel cleaning.

"Dry" cleaning methods are quite effective, but the cost of magnesol and ion exchange resins is quite high, which significantly increases the cost of produced biodiesel. In addition, manufacturers of ion-exchange resins recommend not to exceed the concentration of 500 grams per ton of soap in crude biodiesel, otherwise the quality of cleaning is reduced. Therefore, in order to reduce costs, it is recommended to pre-purify biodiesel with other methods. In addition, if biodiesel is heavily contaminated, ion-exchange resins quickly lose their properties and are poorly regenerated.

Wet water purification of biodiesel provides its effective purification from a homogeneous catalyst, but it uses a significant amount of water, which is polluted during

\footnotetext{
*Corresponding author: ievgeniy_antypov@ukr.net
} 
the purification process and creates environmental problems when it is discharged into the sewer [1]. Wet cleaning is carried out with an aerosol and volumetric methods. The aerosol method is that the water sprayed over the biodiesel layer, the droplets of which, passing through the methyl ether, adsorb the pollutant. When volumetric method of washing is underway, the same amount of water and biodiesel are mixed, then they are agitated, settled and the water is drained upheld and the process is repeated many times [2].

Before washing, biodiesel, manufactured using a homogeneous catalyst, requires neutralization [3]. For this purpose, the biodiesel is mixed with acidified water (in the case of an alkaline catalyst), which results in the neutralization of the catalyst with the formation of salts of acids (soaps) that pass into soap stock.

In order to neutralize biodiesel, inorganic and organic acids are used. Applying inorganic acids, hydrochloric acid $\mathrm{HCl}$, sulfuric acid $\mathrm{H}_{2} \mathrm{SO}_{4}(0.5 \%$ solution in water, acidified water to biodiesel ratio is $1: 1)$, phosphoric acid $\mathrm{H}_{3} \mathrm{PO}_{4}(2-10 \%$ solution in water) [1], [4], [ 5] is used. In case of applying organic acids, acetic or citric acid is used. In the case described [6] neutralization was carried out with four strong concentrated inorganic acids, namely phosphoric, sulfuric, hydrochloric, perchloric and with an organic one acetic acid. The most effective has been recognized orthophosphoric acid. Therefore, in many cases [7], [8], [9] phosphoric acid is used to neutralize biodiesel, sometimes sulfuric acid [10], hydrochloric acid or ammonium chloride is being applied [11].

As noted in papers [12] and [13], the advantage of high acid concentration in aqueous solution is the very rapid reaction of the formation of acid salts (saponification) and the zero content of alkaline catalyst in biodiesel, however, while biodiesel has high acidity $(1.7-4,5 \mathrm{mg} / \mathrm{kg}$ ). In the case of low concentrations of acid in aqueous solution (carbon dioxide), the acidity of biodiesel is less than $0.5 \mathrm{~m} / \mathrm{kg}$, but the saponification of biodiesel takes longer.

The paper [12] describes the use of carbon dioxide to neutralize the catalyst. The advantage is that carbon dioxide does not convert soap into fatty acids, but only neutralizes the catalyst (the acid number is always less than $0.2 \mathrm{mg} \mathrm{KOH} / \mathrm{g}$ ). Neutralization occurs due to excess $\mathrm{CO}_{2}$, which transforms the catalyst into bicarbonate. The document describes [1] how distilled water was used to neutralize biodiesel to prevent the formation of emulsions.

The Paper [9] demonstrates how the neutralization of biodiesel was carried out at a temperature of $65^{\circ} \mathrm{C}$ by mixing it with a mechanical stirrer with acidified water at a stirring rate of $1000 \mathrm{rpm}$. In the document [14], the temperature of the rinse water was $85^{\circ} \mathrm{C}$. In another document [1], the study of neutralization of biodiesel was carried out at various temperatures of an aqueous solution of acid: $50-70{ }^{\circ} \mathrm{C}$ with neutralization by orthophosphoric acid, $55^{\circ} \mathrm{C}$ - sulfuric acid, $20^{\circ} \mathrm{C}$ - hydrochloric acid.

Consequently, from the analysis of previous studies it follows that the neutralization of biodiesel can be carried out both with inorganic (phosphoric, sulfuric, hydrochloric, perchloric) and organic (acetic, citric) acids. Strong acids can accelerate the process of neutralization, but it is difficult to control the process itself, therefore often biodiesel is peroxided. This problem, as a rule, does not exist in the application of weak acids, but the process of neutralization takes more time. Technology and technical means of neutralization in literary sources are poorly covered, there is only mention of the fact that studies were carried out to neutralize biodiesel at a temperature of $20^{\circ} \mathrm{C}, 55^{\circ} \mathrm{C}, 65^{\circ} \mathrm{C}, 70$ ${ }^{\circ} \mathrm{C}$ and $80^{\circ} \mathrm{C}$, and also that in one of the experiments neutralization was carried out by mixing biodiesel with a mechanical stirrer with acidified water at a stirring rate of 1000 rpm.

Therefore, the task of our study is: the definition of an effective method for neutralizing biodiesel; establishment of optimal and rational parameters of neutralization of biodiesel. 


\section{Materials and methods}

Studies were conducted to investigate the effectiveness of neutralizing biodiesel by mixing it with an aqueous solution of citric acid and by spraying an aqueous solution of citric acid over a biodiesel layer.

Experimental investigation method of neutralization of methyl ether by its mixing with aqueous citric acid solution.

Methyl ether for research is made from bilberry oil (83\%), to which potassium methylate $(17 \%)$ is added. Potassium methylate is prepared at a ratio of methanol to $\mathrm{KOH}$ as 10 to 0.6 . The components are mixed on a magnetic stirrer at a temperature of $40{ }^{\circ} \mathrm{C}$ for $15 \mathrm{~min}$, after which the reaction products are poured into a separating funnel, where they are separated for two hours on methyl ether and crude glycerin.

As a result, $82 \%$ of methyl ether and $18 \%$ of raw glycerol are obtained. The raw glycerin is merged, and from the methyl ester the excess of methanol $(0,9 \%$ of the volume of methyl ester) is removed by distillation at $65^{\circ} \mathrm{C}$, at constant aeration by air.

Determination of the effect of the mixer parameters on the alkalinity of the methyl ether during its purification is carried out on a laboratory installation consisting of a liquid thermostat TZH-TS-01/16 and a top-drive mixer EUROSTAR digital.

The test sample of methyl ether purified from methanol in a volume of $300 \mathrm{ml}$ is poured into a 0.5 liter laboratory glass, which is fixed to the tripod, and placed in water, poured into a liquid thermostat (Fig. 1).

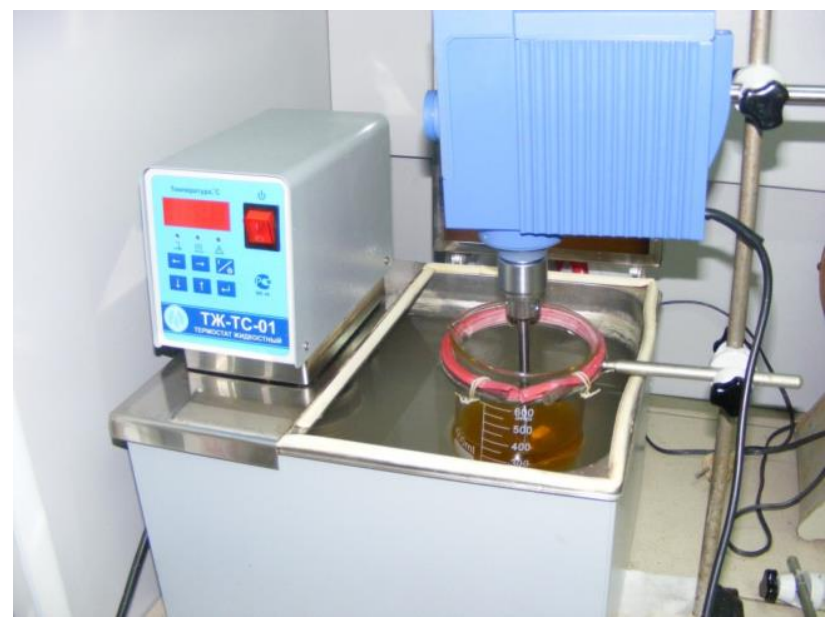

Fig.1. Laboratory installation for determining the influence of mixer parameters on the alkalinity of methyl ether.

On the same tripod, a top-drive mixer with a four-blade stirrer with sloping blades is fixed. With the help of the regulator, the required speed of the shaft of the mixer is set.

$1 \%$ aqueous citric acid solution at the ratio of $5,5 \mathrm{ml}$ per $100 \mathrm{ml}$ of methyl ether is added to the methyl ether. That is, $16,5 \mathrm{ml}$ of a $1 \%$ aqueous solution of citric acid is added to $300 \mathrm{ml}$ of methyl ether.

The study on the effect of the mixer parameters on the alkalinity of the neutralized methyl ester is carried out at temperatures of $20^{\circ} \mathrm{C}, 40^{\circ} \mathrm{C}, 60^{\circ} \mathrm{C}$ and $80^{\circ} \mathrm{C}$, and the rotational speed of the shaft of the stirrer is: 200; 350; 500 and 650 rpm (Fig. 2). Mixing time is 5 minutes. 


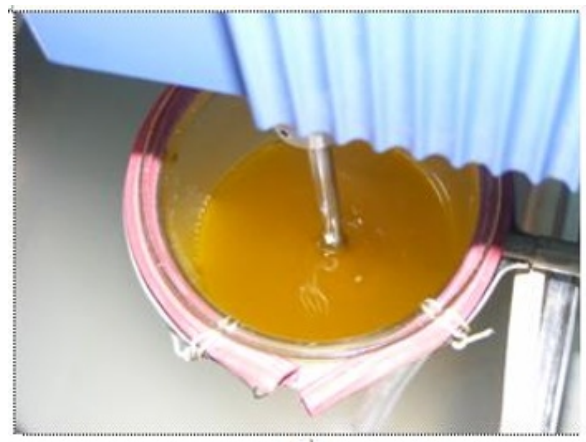

a)

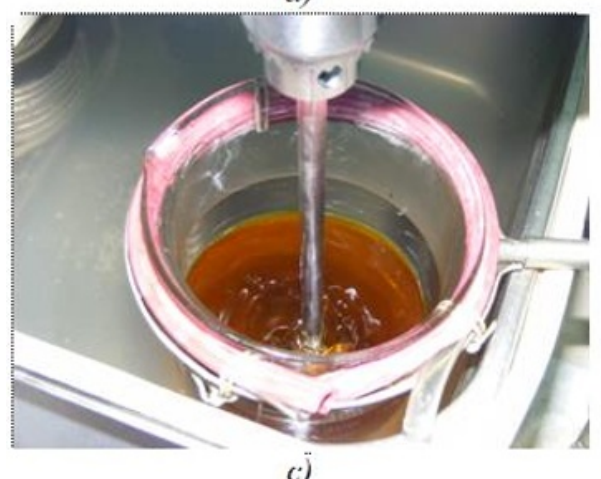

c)

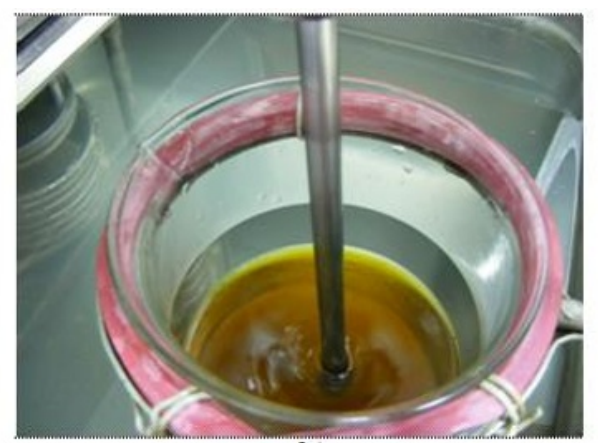

b)

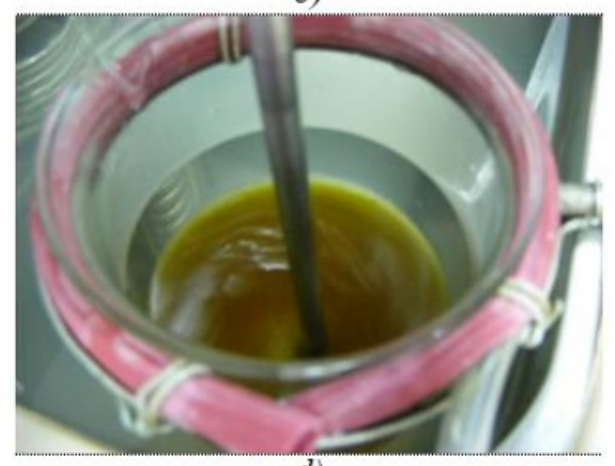

d)

Fig. 2. Neutralization of the methyl ester while mixing with the rotational speed of the shaft of the mixer: a) $200 \mathrm{rpm}$; b) $350 \mathrm{rpm}$; c) up to $500 \mathrm{rpm}$; d) up to $650 \mathrm{rpm}$.

As can be seen from Fig. 2, the rotational speed of the shaft of the mixer of $200 \mathrm{rpm}$ does not cause disturbances of the methyl ether, and its movement in a glass is close to laminar. With increasing frequency of the rotational speed of the shaft of the mixer in a methyl ester there appears a funnel whose depth increases with the increase of the rotational speed of the shaft of the mixer, and at a speed of $650 \mathrm{rpm}$ the bottom of the funnel almost reaches the blades of the mixer.

After neutralization, the methyl ether is poured into dividing funnels (Fig. 3, a) or polyethylene bottles (fig. 3, b) and is settled for 2-3 days (with increasing temperature the time of settling decreases). Protecting methyl ester in polyethylene bottles is carried out if the number of available dividing funnels and tripods on which they are attached is not enough to settle all the samples. While settling a soapstock gravitates on the bottom of the bottle or funnel. The soapstock is a salt (citrate) of potassium and soap formed as a result of neutralization of potassium hydroxide with citric acid (fig. 3, c), and the methyl content of the mud becomes transparent.

Lighted methyl ester is being merged. Drainage of methyl ester from the dividing funnel is carried out as follows. Under the dividing funnel a vessel is placed. There is a crane on the dividing funnel. The crane is being opening and potassium citrate is being draining off from the funnel. The completeness of potassium citrate draining process is controlled visually. In the absence of potassium citrate in the dividing funnel, the crane is being closed. A pot with potassium citrate is being removed from the dividing funnel and a clean vessel is being placed underneath it. The crane on the dividing funnel is being opened again and the entire methyl ester is being poured into the vessel. 


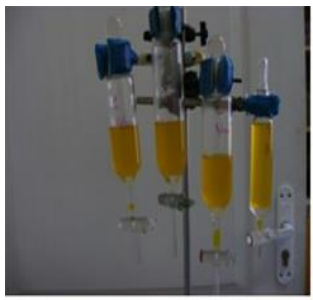

a)

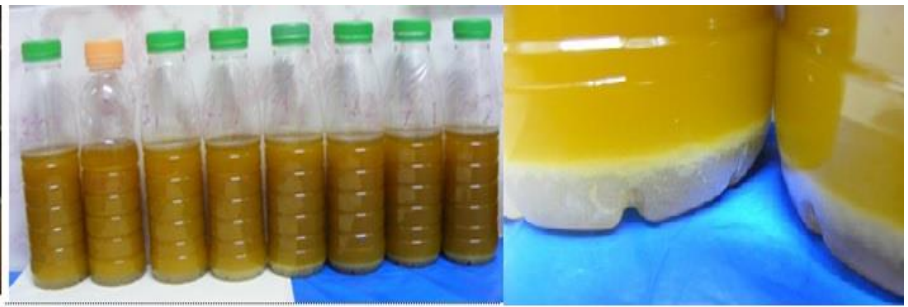

b)

c)

Fig. 3. A process of neutralized biodiesel settling: a) - in dividing funnels; b) - poured into polyethylene bottles; c) - saturation of potassium citrate on the bottom of a plastic bottle.

Draining of the settled methyl ester from a polyethylene bottle is carried out through its neck by deflection of the bottle, while avoiding entering into the methyl ester of potassium citrate, which has accumulated at the bottom of the bottle.

In the obtained samples of neutralized methyl ether, its alkalinity is determined. Method of experimental study of neutralization of methyl ether by spraying an aqueous citric acid solution on it. Determination of the influence of spray parameters on alkaline biodiesel is determined on an experimental installation consisting of a hydraulic pump constructed from a tank of a garden sprayer, a compressor "Atlant" from a refrigerator to maintain a predetermined pressure and a spray gun "Disc and Core" installed in the body with a safety valve (Fig. 4). The liquid pressure is controlled by a pressure gauge.

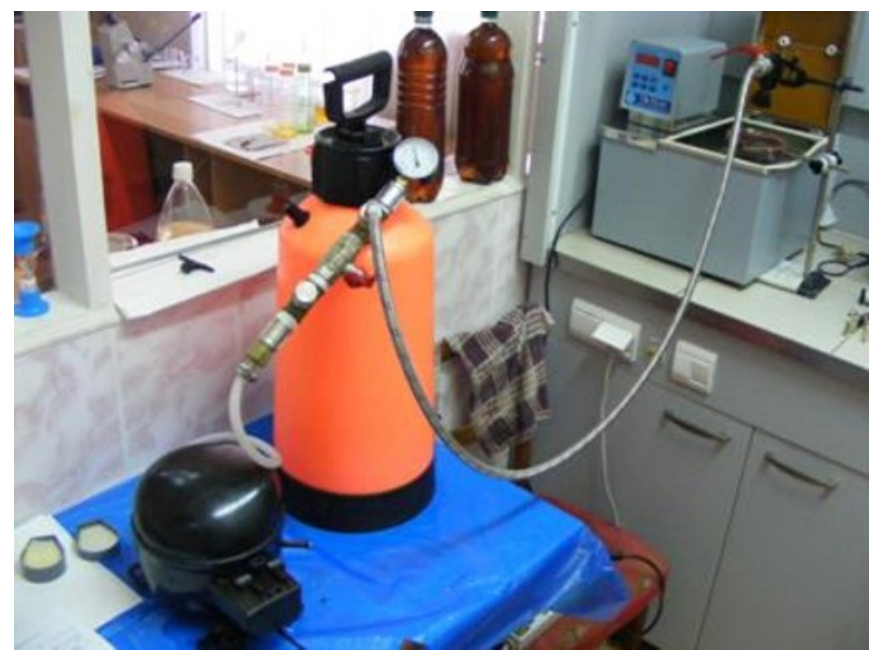

Fig. 4. Experimental installation for determining the influence of spray parameters on the alkalinity of methyl ether.

The effect of the spray parameters on the alkalinity of the methyl ether is determined by spraying of $6 \mathrm{ml}$ of an aqueous solution of $1 \%$ citric acid on $100 \mathrm{ml}$ of methyl ether through a centrifugal full-groove dispenser Disc and Core made by TeeJet which includes a body with one nozzle QJ17560A-NJB, bayonet cap CP 26277-1 -NY, core-turbulator DCCER, ceramic disc with hole DCER-2 and rubber sealant SR-18999 (fig. 5).

The test sample of $300 \mathrm{ml}$ methyl ester purified from methanol is poured into a 500-ml laboratory glass, which is fixed to a tripod, and put into water, poured into a liquid TZHTS-01/16 thermostat. In the sample of methyl ether, $18 \mathrm{ml}$ of aqueous solution of $1 \%$ citric acid is sprayed with a spray gun fixed on the same tripod (Fig. 6).

The spraying time is determined experimentally by measuring the volume of the spray liquid collected in a laboratory glass over a period of time fixed with the "Agat" stopwatch. 
The spraying time is $1,5 \mathrm{sec}$ at a pressure of $0,25 \mathrm{ATM}, 2 \mathrm{sec}$ at a pressure of 0,2 ATM, $2,5 \mathrm{sec}$ at a pressure of $0,15 \mathrm{ATM}$ and 3 seconds at a pressure of 0,1 ATM.

At a given pressure for a fixed time, $1 \%$ of citric acid is sprayed into the test sample of methyl ether (Fig. 7).

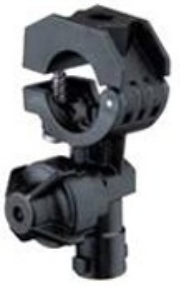

a)

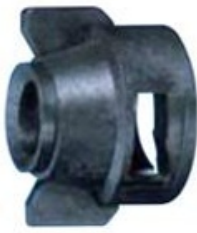

b)

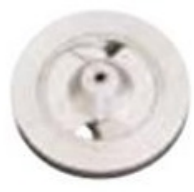

c)

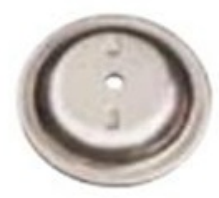

d)

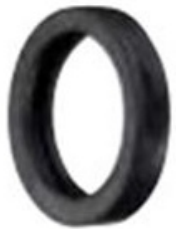

e)

Fig. 5. Centrifugal full spray dispenser Disc and Core: a - body with one nozzle QJ17560A-NJB; b bayonet cap CP 26277-1-NY; c - core-turbulator DC-CEP; d - ceramic disk with a hole DCER-2; e Rubber seal SR-18999.

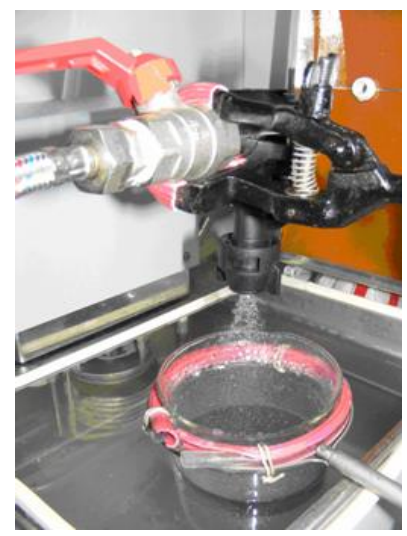

Fig. 6. Spraying aqueous solution of $1 \%$ citric acid in the test sample of methyl ether.

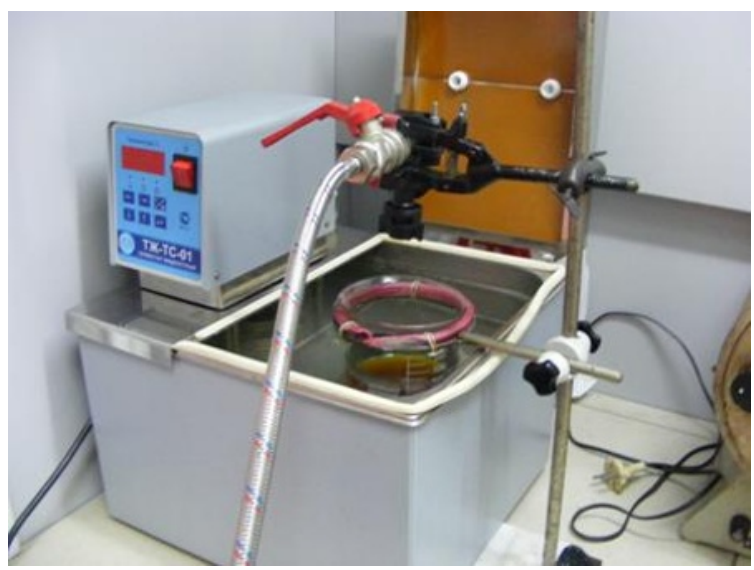

Fig. 7. Spraying $1 \%$ citric acid in the sample of methyl ether to determine the effect of the spray parameters on the alkalinity of the methyl ether. 


\section{Results of research}

The results of determining the effect of the mixer parameters on the neutralization efficiency of methyl ether when mixed with a solution of citric acid are shown in Fig. 8.

Initial alkalinity of methyl ester was $37,9 \mathrm{mg} / \mathrm{kg}$. As can be seen from Fig. 8, the decrease of the alkalinity of methyl ether is observed at an increase in the temperature at which the neutralization process passes. At a temperature of neutralization of $20^{\circ} \mathrm{C}$, it is not possible to achieve the alkalinity of methyl ester below $5 \mathrm{mg} / \mathrm{kg}$ (according to DIN 51606 standard) at any value of the speed of the shaft of the mixer.

At a neutralization temperature of $40^{\circ} \mathrm{C}$, the optimum rotational speed of the shaft of the mixer, at which the alkalinity of the methyl ether becomes less than $5 \mathrm{mg} / \mathrm{kg}$ (namely 3,7 $\mathrm{mg} / \mathrm{kg}$ ), is $350 \mathrm{rpm}$. The allowable rotational speed of the mixer is in the range of 300-400 rpm.

With an increase in the neutralization temperature, the optimization point is shifted to larger rotational speeds of the shaft of the mixer. Thus, at temperatures of $60^{\circ} \mathrm{C}$ and $80^{\circ} \mathrm{C}$, the alkalinity of biodiesel below $5 \mathrm{mg} / \mathrm{kg}$ is already observed at the speed of the shaft of the mixer of $550 \mathrm{rpm}$. With an increase in the speed of the shaft of the mixer, the alkalinity of neutralized biodiesel decreases. It is not possible to set the extreme right point of the rational neutralization range, since experiments with the speed of the shaft of the mixer more than $650 \mathrm{rpm}$ were not conducted.

The results of the experimental study of the neutralization of methyl ether by spraying an aqueous citric acid solution on it are shown in Fig. 9.

Initial alkalinity of methyl ether in the experiments was $37,9 \mathrm{mg} / \mathrm{kg}$. As can be seen from Fig. 9, when the pressure increases in the sprayer and the temperature of the test sample increases, the alkalinity of the methyl ether decreases, but On the whole range of the investigated values of pressures and temperatures the alkalinity does not drop below 5 $\mathrm{mg} / \mathrm{kg}$ in accordance with DIN 51606. Therefore, the use of liquid spray to neutralizing the methyl ester is not effective.

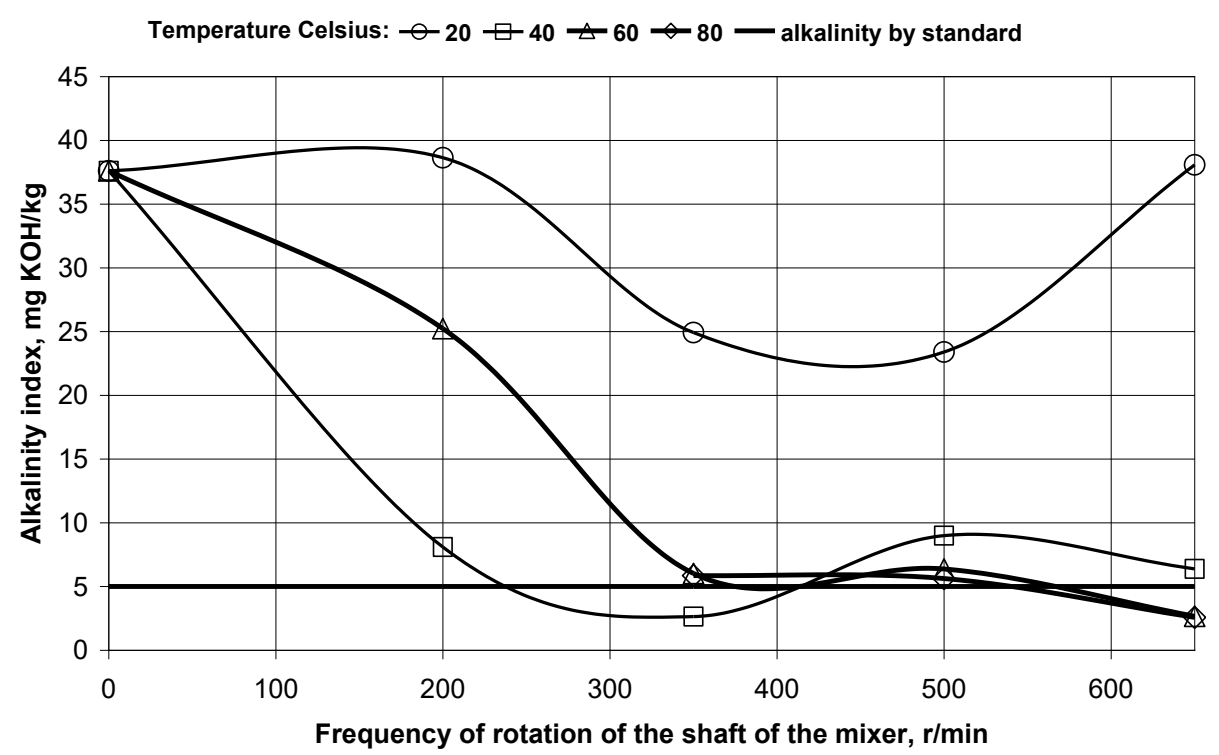

Fig. 8. Dependence of the alkali of methyl ether on the frequency of rotation of the mixer when it is neutralized. 


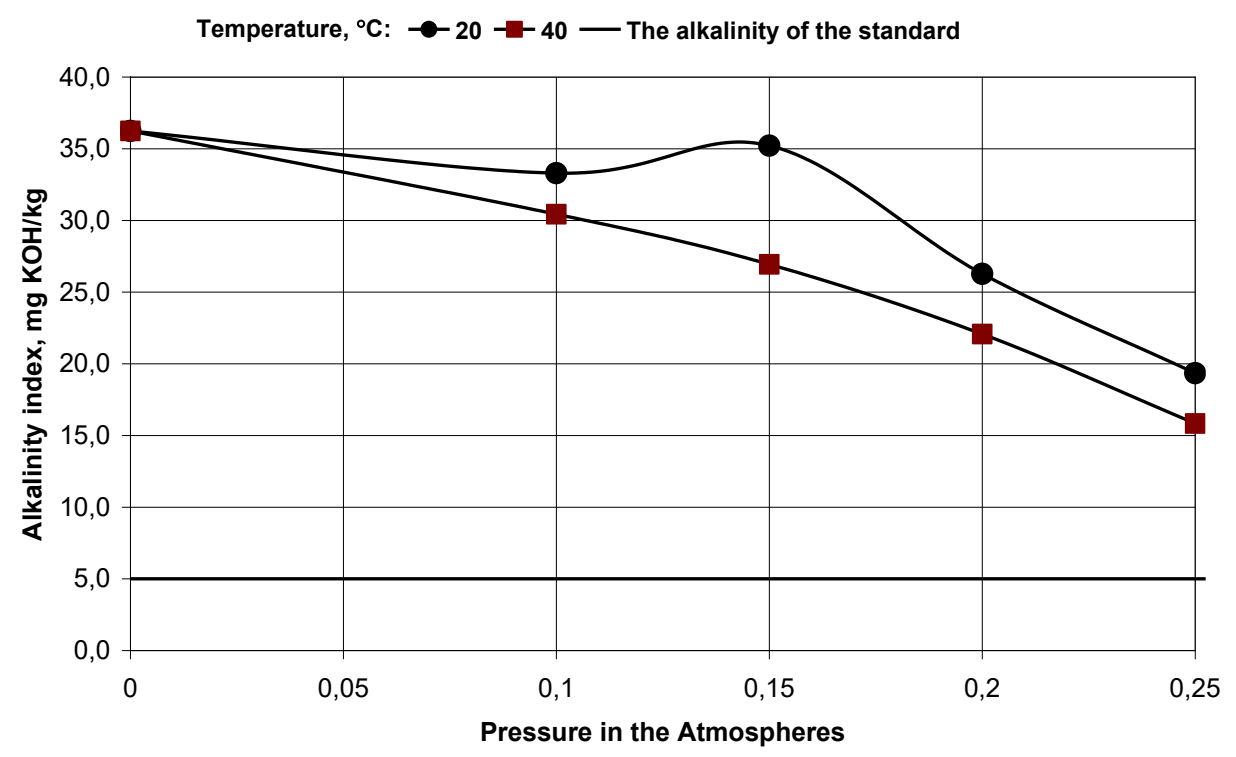

Fig. 9. Dependence of alkalinity of the methyl ester from pressure of the sprayer during its neutralization.

\section{Conclusions}

1. It is advisable to neutralize biodiesel by volumetric method by mixing it with acidified water. The use of an aerosolized method of neutralizing biodiesel is inappropriate due to its low efficiency.

2. At a neutralization temperature of $40^{\circ} \mathrm{C}$, the optimum rotational speed of the shaft of the mixer, at which the alkalinity of the methyl ether becomes less than $5 \mathrm{mg} / \mathrm{kg}$, is $350 \mathrm{rpm}$ and the allowable one is $300-400 \mathrm{rpm}$. With an increase in the neutralization temperature, the optimization point is shifted to larger rotational speeds of the shaft of the mixer. At temperatures of $60^{\circ} \mathrm{C}$ and $80^{\circ} \mathrm{C}$, the alkalinity of biodiesel below $5 \mathrm{mg} / \mathrm{kg}$ is already observed at the speed of the shaft of the mixer of $550 \mathrm{rpm}$ and above.

\section{References}

1. I.M. Atadashi, M.K. Aroua, A.R. Abdul Aziz, N.M.N. Sulaiman, Applied Energy, 88(12), 4239-4251, doi: 10.1016/j.apenergy.2011.05.029 (2011)

2. M. Alovert, Biodiesel homebrew guide: everything you need to know to make quality alternative diesel fuel out of waste restaurant fryer oil, 115 (2007)

3. K.G. Georgogianni, A.K. Katsoulidis, P.J. Pomonis, G. Manos, M.G. Kontominas, Fuel Processing Technology, 90(7-8), 1016 -1022, doi: 10.1016/j.fuproc.2009.03.002 (2009)

A. Casas, A. Perez, M.J. Ramos, Organic process research \& development, 21(9), 1253-1258, doi: 10.1021/acs.oprd.7600108 (2017)

4. M. Hajek, F. Skopal, Bioresource Technology, 101(9), 3242-3245, doi: 10.1016/j.biortech.2009.12.094 (2010)

5. S. Sadhukhan, U. Sarkar, Energy Conversion and Management, 118, 450-458, 10.1016/j.enconman.2016.03.088 (2016)

6. A.L. Esipovich, A.E. Rogozhin, A.S. Belousov, E.A.Kanakov, S.M. Danov, Fuel Processing Technology, 173, 153-164, doi: 10.1016/j.fuproc.2018.01.023 (2018)

7. S.B.Glisic, D.U. Skala, Chemical Industry \& Chemical Engineering Quarterly, 13(3), 159-168, 
doi: 10.2298/CICEQ0903159G (2009)

8. N. Akgun, E. Iscan, European Journal of Lipid Science and Technology, 109(5), 486-492, doi: 10.1002/ejlt.200600210 (2007)

9. F. Karaosmanoglu, K.B. Cigizoglu, M. Tuter, S. Ertekin, Energy \& Fuels, 10(4), 890-895, doi: 10.1021/ef9502214 (1996)

10. K.V. Sandhya, S. Abinandan, N. Vedaraman, K.C. Velappan, Waste Management, 48, 638-643, doi: 10.1016/j.wasman.2015.09.033 (2016)

11. M. Hajek, F. Skopal, A. Vavra, J. Kocik, Journal of cleaner production, 155(1), 28-33, doi: 10.1016/j.jclepro.2016.07.007 (2017)

A. Vavra, M. Hajek, F. Skopal, Renewable energy, 103, 695-700, 10.1016/j.renene.2016.10.084 (2017)

12. M.G. Gomes, D.Q. Santos, L.C. de Morais, D. Pasquini, Fuel, 155, 1-6, doi: 10.1016/j.fuel.2015.04.012 (2015)

13. Petroleum products and lubricants. The neutralization number. Method of potentiometric titration [Nefteprodukty i smazochnye materialy. Chislo nejtralizacii. Metod potenciometricheskogo titrovaniya], GOST 11362-96 from 1d July 1997, Moscow: Standartinform [Interstate]. (1996). 